\title{
EFEITOS IDEOLÓGICOS DA GRAMÁTICA DO DISCURSO DO DIREITO
}

\author{
(Ideological effects of the grammar of the discourse of law)
}

\author{
Dionéia Motta Monte Serrat ${ }^{1}$ \\ Leda Verdiani Tfouni ${ }^{2}$ \\ (Universidade de São Paulo -USP)
}

\begin{abstract}
In the discourse practices within the institution of the Judiciary, a distinction can be established between the concepts of discourse of the Law and juridical discourse. The first corresponds to a ritual of overlapping turns of speech that gives cohesion and a unique sense to the speech; and the juridical discourse corresponds to a "speaking intersubjectivity" (Pêcheux, 1988), which promotes a fracture in the assumed unity of meaning of the discourse of the Law. This movement results in a subject who is an effect of language, divided and opaque. According to the theories of Discourse Analysis (Pêcheux, 1988) and Literacy (Tfouni, 1992, 2005), we observe that the grammar of the discourse of the Law involves a kind of fetishism that uncovers how the ideology and the unconscious operate to delete the subjectivity of the narratives. We suggest a detachment from the ideological effects of that grammar, in order to bring the possibility of studying how the subjects with low literacy degree (Tfouni, 2010) interact within these specific social formations that segregate them.
\end{abstract}

Key words: discourse of Law, juridic discourse, subjectivity, grammar, literacy.

1. Doutoranda em Doutorado Direto em Psicologia pela FFCLRP-USP; bolsista CAPES de estágio de doutorando no exterior set./dez. 2010, CAPES-BEX 4394/10-0 na Universidade Sorbonne-Nouvelle, Paris (co-orientador Prof. JeanJacques Courtine); estágio no exterior fev. 2012, FAPESP 09/54417-4 na École des Hautes Études en Sciences Sociales, EHESS, Paris (orientador Prof. Marcello Carastro).

2. Professora Titular da FFCLRP-USP, pesquisadora do CNPq. 


\section{RESUMO}

Nas práticas jurídico-discursivas podemos distinguir os conceitos de discurso da Lei e discurso jurídico. Podemos observar o primeiro como um ritual de superposição de falas que dá coesão e sentido único à fala; e podemos observar o discurso jurídico como "intersubjetividade falante" (Pêcheux, 1988), que rompe a unidade de sentido do discurso do Direito e leva em conta o sujeito como efeito da linguagem, dividido e opaco. Sob as perspectivas das teorias da Análise do Discurso (Pêcheux, 1988) e do Letramento (Tfouni, 1992, 2005), observamos, no funcionamento da gramática do discurso do Direito, uma espécie de fetichismo que cobre o modo de funcionamento da ideologia $e$ do inconsciente e leva à supressão da subjetividade das narrativas. Sugerimos um distanciamento dos efeitos ideológicos dessa gramática de modo a trazer a possibilidade de estudar o modo como os sujeitos com baixo grau de letramento (Tfouni, 2005) operam dentro dessas formações sociais específicas que os marginaliza.

Palavras-chave: discurso do Direito, discurso jurídico, subjetividade, gramática, letramento.

\section{Introdução}

O discurso do Direito está fundado na Lei e traz a ideia de igualdade de todos que a ela se assujeitam (Brasil, [1988] 2003: art. $5^{\circ}$ ). Ao lado dessa suposta igualdade existe a ideia de transparência da língua, que torna corriqueira a "necessidade" de intervenção do "técnico" do Direito para tratar de questões jurídicas. Assim, sem nos darmos conta, existe, no âmbito do Direito, um modo de operar os discursos, a que chamamos gramática, que divorcia direito e fatos, e torna natural a desvalorização e marginalização dos discursos embebidos na subjetividade de sujeitos com baixo grau de letramento (TFOUNI, 2004).

Nosso objetivo, no âmbito deste estudo, é o de nos distanciarmos dessas supostas "igualdade" e "transparência" do discurso do Direito, para apontar como se dá o percurso social, histórico e psíquico do sentido nas práticas jurídico-discursivas. Segundo as teorias da Análise do Discurso (Pêcheux, 1988), do Letramento (Tfouni, 1992, 2010) e 
da psicanálise lacaniana será possível observarmos como as instituições impõem um sentido dominante por meio de sua gramática. Para essas propostas teóricas, o sentido está sujeito ao equívoco, não é único; e, por meio delas, questionamos a incompatibilidade entre discurso do Direito e discurso jurídico. O conceito de discurso jurídico objeto de nosso enfoque comporta lapsos e falhas no sentido, características que não são admitidas pela imposição do raciocínio silogístico ao discurso do Direito.

A psicanálise lacaniana permitiu-nos articular a Teoria Geral do Estado (Cintra et al, 1981) à teoria do estádio do espelho de Lacan ([1949] 1998) para compreendermos o Estado (Lei) como algo que traça o caminho do desejo do sujeito, como algo que dá a ver a imagem especular de sujeito de direito. O que ocorre, no entanto, é que o sujeito (jurídico) que emerge no momento da enunciação, na cena de uma audiência perante o Poder Judiciário, é aquele que confere um sentido particular ao enunciado, diverso do sentido posto pelo sujeito de direito. Embora possamos entender que no sujeito de direito haja imposição de um único sentido, há algo que rompe essa unidade e a modifica, quebra sua bidimensionalidade e traz à tona outra dimensão, a do sujeito jurídico, em que o sentido é polissêmico.

\section{O funcionamento do discurso do Direito}

Para conhecer a gramática do discurso do Direito, é preciso conhecer o seu funcionamento de discurso embebido do "dever ser". Para estudá-lo desde essa perspectiva deôntica, escolhemos o evento de letramento de uma audiência do Poder Judiciário, momento em que alguém faz seu depoimento perante o juiz de direito. Durante esse acontecimento atentamos para o paradoxo de que a língua, tida como supostamente transparente, coexiste com a necessidade de intermediação do juiz nas falas.

A lei determina como devem ser as intervenções do juiz nas falas em audiência, o que mostra a dimensão jurídica da língua e sua 
efetividade social de uma maneira exacerbada, diferente do juridismo ${ }^{3}$ que permeia as relações sociais de modo mais diluído. Entendemos que o discurso do Direito numa audiência (Brasil [1973], 2007) impõe uma gramática, uma estrutura, um valor, para a enunciação do depoente (introduz um efeito jurídico aos enunciados transcritos para o termo ${ }^{4}$ ) e ignora o discurso jurídico com seus atos falhos e lapsos. Nesse caso, a ordem de sentidos do discurso do Direito constitui uma memória do dizer e determina as relações sociais, segundo Tfouni (1992, 2010) e Pêcheux (1988). O discurso do "dever ser" trabalha na origem do dizer dos sujeitos, fora de um lugar de livre escolha destes. A lei dá "competência" ao juiz para fazer os recortes nas falas das partes a fim de evitar "ambiguidade”, "distorção" (Silva, 1987:145), e isso não seria necessário numa língua "imutável” e "transparente".

O que ocorre, então, por ocasião de um depoimento oral? Segundo nosso ponto de vista, a participação do juiz de direito nas falas, fazendo os recortes e ditando ao escrevente de sala o que deve constar do "termo de audiência" ${ }^{5}$, é crucial para a constituição do sentido daquilo que foi enunciado. Este estudo sobre a relação do sujeito com a linguagem no ambiente jurídico (audiência) nos permite observar os funcionamentos discursivos que trabalham na materialidade da língua.

O discurso do Direito tem suas origens nas relações coercitivas do Estado em relação ao indivíduo, levando à emergência do sujeito de direito (Haroche, 1992). A diferença por nós estabelecida entre discurso do Direito e discurso jurídico nos leva a compreender este último como aplicação formal da lei em contextos institucionalizados, como o funcionamento das relações interpessoais marcadas por relações de poder inscritas numa esfera de tensão denominada juridismo (Lagazzi, 1987).

O funcionamento do discurso do Direito no contexto escolhido para esta pesquisa (Brasil, [1973], 2007) está descrito na lei, que

3. O termo "juridismo" implica relações interpessoais marcadas por relações de poder (Lagazzi, 1987).

4. "Termo" é o nome jurídico para o documento digitado pelo escrevente de sala, cujo conteúdo corresponde àquilo que o juiz lhe ditou logo após ouvir a testemunha, o autor ou o réu.

5. Documento juntado ao processo cujo conteúdo é ditado pelo juiz. 
determina minuciosamente como se dá uma audiência, quais são os poderes e os deveres do juiz e das partes. Ele é o nosso ponto de partida na percepção dos sentidos que circulam no discurso científico e supostamente neutro. Interessa-nos não o conteúdo das falas das partes e do juiz em audiência, mas, a postura científica do dado indiciário, conforme ensina Ginzburg (1989), para colocar em relevo o conhecimento opaco dos dados e o contexto em que foram produzidas as falas. É essa percepção que trará uma contribuição teórica para discernir o que é discurso jurídico, lugar em que o sujeito emerge no paradoxo de que é "livre para se obrigar".

\section{A gramática do discurso do Direito}

A Análise do Discurso pêcheutiana (Pêcheux, 1988) propõe que a ciência do Direito, supostamente neutra, seja enxergada para além da ideia de transparência e de idealismo jurídico, como modo de produção de um funcionamento social que reproduz o Estado, e, ao mesmo tempo, quer ser visto desvinculado dos fenômenos sociais. A materialidade discursiva associada à visão crítica sobre o discurso do Direito (Miaille, 1979; Tfouni, 2010; Pêcheux, 1988, Haroche, 1992), permite que enxerguemos a perda de unidimensionalidade deste último, expondo o fosso existente entre a teoria jurídica e sua prática.

Existe uma coação inerente às normas que traz a impressão de transparência e faz o foco sair da realidade e ir para as ideias (Miaille, 1979). Se nos distanciarmos desse ponto de vista, poderemos pensar a materialidade discursiva das falas realizadas durante as audiências do Poder Judiciário como um lugar onde se pode observar o sujeito cindido, ou seja, aquele que ocupa a posição-sujeito de direito ("aquele que é para a lei”) (Haroche, 1992) e o que ocupa a posição-sujeito jurídico (aquele que emerge no discurso jurídico, com características discordantes da estrutura rígida que dá forma ao sujeito de direito). Com a visão de que o contexto sócio-histórico dá origem à ciência do Direito é possível compreender o caráter artificial da noção de sujeito de 
direito, pois, juntamente com a noção de Estado, representam "formas jurídicas necessárias” a uma sociedade capitalista (Miaille, 1979:107). Para funcionar, o capitalismo supõe a "atomização", a "representação ideológica da sociedade como um conjunto de indivíduos separados e livres" (Miaille, 1979:111), fenômenos compreendidos aqui sob o conceito de sujeito de direito. Nessa categoria de sujeito de direito, é possível perceber que não existe liberdade, nem igualdade, e que o Estado ocupa o pilar do sistema jurídico (op. cit.:128).

Podemos afirmar, então, que o sistema jurídico reproduz o Estado e o sujeito de direito. Para questioná-los é preciso deslocá-los da lógica (gramática) jurídica e submetê-los ao corte epistemológico, enxergar a lógica jurídica como algo que divorcia direito e fatos (Pêcheux, 1988:196; Miaille, 1979:170). A relação econômica depende da relação política e social. A formação social não é um lugar de justaposição, mas de uma unidade, mesmo que contraditória (Miaille, 1979:198). O Direito, por ter hegemonia no sistema de comunicação capitalista, traz, na norma, a ideia de "troca equivalente" e é marcado pelo idealismo, que encobre sob "relações livres e iguais", a relação entre proprietário do capital e proprietário da força de trabalho (op. cit.).

Se compreendermos o conceito de sujeito de direito como "forma plenamente visível da autonomia" (Pêcheux, 1988), como "forma-sujeito" (op. cit.), poderemos observar também que sua vontade está ligada não apenas a uma "orientação da pessoa em direção da ação", mas também a uma "valorização do agir” (Lagazzi, 1988:20). Seu significado é o de alguém que é "submetido à autoridade soberana", "que é subordinado" (Haroche, 1992:158) e implica um só discurso possível, onde não há lugar para "fazer valer um desejo próprio" (Legendre 1976 apud Haroche, 1992:158). O discurso do Direito obscurece, sob a suposta transparência da linguagem, o "caráter material do sentido das palavras e dos enunciados" (Pêcheux, 1988:160). Isso ocorre porque, segundo ensina Pêcheux (apud Guimarães 2002:14), o sujeito fala de um lugar no interdiscurso em que a memória é estruturada pelo esquecimento de que já significa.

À imagem do sujeito de direito se constitui o sujeito do direito, que, neste estudo, é aquele que ocupa a posição discursiva de juiz 
de direito dentro de determinada sociedade e desempenha uma função determinada, em que a transmissão de sua vontade é prevista e organizada pela lei (Miaille 1979:132 e 137). É aquele que, na burocracia "procede dos escritos da lei, e não tem nada a dizer que the seja próprio"; aquele cujo desejo é mantido como "legal satisfação" (Legendre 1976, apud Haroche, 1992:190). Sujeito do direito é aquele que tem "competência jurídica", que faz um trabalho de construção da gramática do Direito; que, mediante uma seleção das propriedades pertinentes, permite reduzir a realidade à sua definição jurídica, essa "ficção eficaz" (Bourdieu, 1998:233). Para melhor distingui-los, colocamos o sujeito jurídico como o que corresponde ao funcionamento da estrutura discursiva a que Pêcheux (1988:163164 e 183) denomina "forma-sujeito". Sob esse funcionamento, o sujeito jurídico não reconhece sua subordinação, seu assujeitamento ao Outro (Estado), pois se assujeita sob a forma da autonomia. O sujeito jurídico é constituído sob os efeitos de sentido que circulam no contexto da audiência, em que a lei dita o que deve ou não deve ser feito, o que pode e o que não pode ser dito.

Segundo Tfouni (1992:35) o discurso do Direito é monológico, não admite múltiplas leituras, e pressupõe uma autoridade de imposição de quem o produz. Situa-se no nível mais sofisticado do uso da escrita, como linguagem técnica e oficial (Tfouni, 2007:155) e cria uma "barreira linguística", enfim, uma gramática em que se encobre a ordem "igualar para melhor dominar". Por meio desse entendimento, podemos concordar com Dinamarco (2000:478) e afirmar que a atuação do juiz de direito no procedimento judicial da audiência é incompatível com sua liberdade de conduta, pois não atua para defender interesses próprios e o poder que exerce não é seu, mas o do Estado. O controle dos sentidos que circulam no contexto da audiência é dado, pela lei, ao juiz. Este faz os recortes das falas e dita o que ouviu para o escrivão; tem a incumbência, implícita, de administrar a produção e circulação dos sentidos para formar o "consenso".

É assim que, segundo Pêcheux (2002), se cria uma ilusão do mundo como "semanticamente estabilizado". A gramática do discurso do Direito cria, no caso das audiências em estudo, um lugar 
onde todos parecem pensar e agir de igual modo, pois o fato de os depoimentos serem tomados como "ambíguos" ou não "claros" leva à suposta necessidade de o juiz "corrigi-los". Ensinam os juristas (Silva, 1987:145) que: "A obscuridade indica falta de clareza. E o juiz a remove, suprindo a deficiência”.

Nossa proposta é a de compreendermos essa gramática, esse funcionamento do discurso do Direito de outro modo, fora de sua "lógica". Quando Miaille (1979) compara a lógica jurídica ao funcionamento da gramática, o faz para dizer que há nesse funcionamento uma abstração de conteúdo em favor da forma, a fim de que o pensamento seja coerente. Para ele (op. cit.:170), a lógica jurídica vai além da gramática, pois ao constituir o pensamento, constrói alguns conceitos que eliminam o conteúdo concreto para o qual remete. A lógica jurídica reúne termos, classifica-os de modo a construir uma unidade para o sistema jurídico. O discurso do Direito, portanto, ao funcionar dentro da lógica jurídica, exclui contradições, leva ao controle dos sentidos por meio de uma ideologia dominante, produz uma voz social homogênea. Ao priorizar uma linguagem "transparente", com um só sentido, ele produz "discursos monologizantes, totalizantes, 'científicos', 'descentrados”' (Tfouni, 1992:100). Ressaltamos que isso se dá dentro de práticas e de instituições sociais onde há imposição do sentido; este se materializa em práticas discursivas que, por sua vez, irão determinar as posições de sujeito, posições discursivas que não estão disponíveis para todos (op. cit.:104-105).

\section{Sujeito e práticas discursivas: discurso do Direito $X$ discurso jurídico}

Os modos de produção do sentido e de constituição do sujeito nos ritos e práticas jurídicas realizados durante audiências do Poder Judiciário envolvem efeitos ideológicos e, segundo lição de Ginzburg (1989), tentaremos dissolver as névoas da ideologia. De acordo com as teorias da AD (Pêcheux, 1988), do Letramento (Tfouni, 1992, 2005) e da psicanálise lacaniana (Lacan [1949]1998), podemos 
observar a relação sujeito-grande Outro, no corpus, para além do "achar" do pesquisador, pois ao relacionarmos o discurso, efeito de sentidos, de recortes desse corpus, com o exterior da língua, podemos compreender como se dá o processo de produção do discurso do Direito e do discurso jurídico.

Dentro do que chamamos de discurso do Direito, observamos que os sujeitos ocupam posição, alocada pela lei, de autor, de réu, de juiz, de escrevente de sala, no contexto de audiência em Vara Cível da Justiça Estadual; observamos também que formações discursivas os influenciam naquilo que podem ou devem dizer. Esses sujeitos ocupam, em seu discurso, uma posição determinada pelo jurídico, pois as falas partem da lei, são disciplinadas pela lei e a ela retornam. É importante lembrar, neste momento, que a constituição do sujeito se dá no campo da linguagem, o que permite nosso estudo sobre o assujeitamento dos sujeitos.

O discurso jurídico, por sua vez, é compreendido na cena da audiência, condição em que foram produzidas as enunciações, influenciando efeitos de sentido do dizer. Ao enunciar, o sujeito depoente ou o sujeito que ocupa a posição de juiz se constitui em sujeito do discurso e é assujeitado pelas circunstâncias de sua enunciação. Os sentidos que circulam numa audiência do Poder Judiciário são determinados pela ideologia (Pêcheux, 1988) inerente a esse Poder e pela constituição psíquica do sujeito (Lacan [1949][1960]1998; [1953-1954]1986; [1954-1955]1987; 1992, [1957]1998).

Nesse estudo discursivo desenvolvido durante o acontecimento de uma audiência em Vara Cível do Poder Judiciário estadual, há influência do contexto sócio-histórico e ideológico da instituição do Estado, o Poder Judiciário. Isso compreende um pressuposto, um nãodito, presente na Lei (Brasil [1973], 2007), que impede que se faça justiça pelas próprias mãos; leva o sujeito à prática de uma série de atos regulados por lei disciplinadora do procedimento judicial; organiza práticas e ritmos das falas e da escrita na audiência influenciando a prática discursiva (a lei prevê o que pode e o que não pode ser dito ou escrito); determina a forma de o juiz elaborar sua decisão ao ditar ou escrever sua sentença. É nesse contexto que coletamos dados para 
análise a fim de estabelecer diferença entre sujeito jurídico e sujeito de direito. As falas em audiência foram gravadas e posteriormente transcritas, a fim de serem comparadas aos "termos de audiência", ditados pelo juiz e digitados pelo escrevente de sala. É nessa superfície linguística que iniciamos um estudo da "dupla ilusão" (Pêcheux, 1988) do sujeito, para observar, sob nova perspectiva, o fato de que o sujeito teria supostas autonomia e consciência de seu discurso, ou para observar que aquilo que diz seria exatamente correspondente ao que ele pensa (ocasiões em que o sujeito ignora que há um discurso preexistente ao seu, no caso, o discurso da lei).

Sob o ponto de vista da Análise do Discurso e do Letramento, o sujeito não nasce nem se desenvolve, mas se constitui, e essa constituição abarca, também, o sujeito do inconsciente, articulada que é ao plano social (Elia, 2004:36). A noção de sujeito, para a teoria psicanalítica, é a de que ele é "ato de resposta" (op. cit.:41) ao grande Outro, e esse encontro entre sujeito e Outro "cria o passado" que passa a atuar como "anterioridade determinante" (op. cit.: 43-44). A Análise do Discurso parte do discurso enunciado, buscando as formações discursivas a que se filia, chegando à formação ideológica que revelará, por fim, a formação social que a determinou. Língua e psicanálise se entrecruzam neste estudo, pois, "o fato de que haja língua tem a ver com o fato de que haja inconsciente" (MILNER, 1987:42).

Quando confrontamos os conceitos de sujeito de direito e sujeito jurídico segundo as bases teóricas deste estudo, podemos afirmar, resumidamente que: o discurso do Direito, "fornece-impõe" a realidade, e, juntamente com ela, o seu "sentido" (Pêcheux, 1988:164), fornece a imagem do sujeito de direito. Fica dissipada, dentro do discurso jurídico, a evidência da transparência de linguagem do discurso do Direito, aquilo "que é" e "o que deve ser" do sujeito de direito, pois no discurso jurídico emerge o sujeito jurídico, assujeitado, num "jogo de efeitos ideológicos" (Pêcheux, 1988:153), presente em todo discurso, assujeitado aos efeitos de sentido sob a "forma plenamente visível da autonomia" (Pêcheux, 1988:159). O modo de ser da "ciência régia" (Pêcheux, 2002) do Direito, a que denominamos discurso do Direito, 
encobre o caráter material do sentido das palavras e dos enunciados (Pêcheux, 1988:160), constituindo, sob esse funcionamento de "evidência" e de "autonomia", o sujeito jurídico.

A visão discursiva (Tfouni, 1992, 2010; Pêcheux, 1988) sobre as supostas "estabilidade" e "transparência" da escrita do juiz no "termo de audiência" - trouxe nova perspectiva sobre o estudo das paráfrases feitas pelo juiz a respeito dos depoimentos das partes (autor ou réu), ou das testemunhas (posteriormente transformados em documento escrito por meio de ditado).

Ao comparamos as falas gravadas e transcritas com o conteúdo fixado no "termo de audiência", foi possível observar uma não coincidência entre a imposição de padrões de dizer e fazer da gramática do discurso do Direito (enunciado) e o surgimento de atos falhos, lapsos do sujeito jurídico (enunciação). Observamos que existe uma aparente autonomia dos depoentes e do juiz; e, também, a evidência de que a participação mais eficaz é a dos indivíduos que dominam a escrita.

Seguindo trabalho de Tfouni (2010), propomos neste estudo que se leve em consideração a narrativa, lugar que possibilita a inserção da subjetividade e permite ao sujeito deslocar-se para outra região discursiva, significando de outro modo, pois "existe uma tensão constante entre alíngua e língua" (Tfouni 2007) e os atos falhos são "momentos mal sucedidos" nessa tensão (Tfouni, 2008).

Nossa análise discursiva das falas em audiência tem, como finalidade, argumentar sobre alguns fatos linguístico-enunciativos que, desprezados pelo sistema jurídico, tornam-se relevantes, pois evidenciam que a língua é opaca e que o sujeito é falho (ao contrário do que estabelece o discurso do Direito, que tem a língua como transparente e o sujeito como mensurável e predizível) (Tfouni, 1992, 2010; Pêcheux, 1988; Lacan [1949][1960]1998; [1953-1954]1986; [1954-1955]1987; 1992; [1957]1998). Em nossa posição de pesquisadoras, distanciamo-nos da análise da forma da enunciação e nos detivemos no contexto da enunciação. Torna-se, pois, relevante o contexto social e histórico que dá origem às falas dos depoentes e às funções do juiz, ou melhor, ao sujeito jurídico como efeito de sentidos. 
O contexto da audiência remete, portanto, ao Poder Judiciário como Aparelho Ideológico do Estado (AIE) (Althusser,1999), o que é de fundamental importância para apreciar os recortes do corpus dentro da teoria materialista dos processos discursivos (Pêcheux, 1988).

O sujeito de nosso estudo é observado não só sob as dimensões social e lógica, mas também sob a dimensão política (Zarka, 2004:129). Isso nos leva a utilizar a teoria psicanalítica para propor o estudo da relação entre o Estado e a constituição do sujeito jurídico a partir do texto "o estádio do espelho" de Lacan ([1949]1998), em que a constituição do sujeito se dá a partir da imagem especular; em que o estatuto do objeto do olhar é o de causador do sujeito. Com esse pressuposto, podemos compreender que, na imagem especular, o sujeito se vê como o outro vê. Algo do funcionamento do sujeito fica recalcado devido a uma "necessidade" de não contradição no que diz respeito ao "amor ao Estado" (ORLANDI, 1996).

Ao estabelecermos a relação entre sujeito e Estado a partir do texto de Lacan ([1949]1998) sobre o estádio do espelho podemos compreender que a imagem especular supõe um aparato que condiciona a constituição desse sujeito (Melenotte, 2006); assim, associamos esse aparato ao Estado em sua relação com o sujeito. O grande Outro (Estado, na posição de espelho "A") é aquele a partir do qual o discurso se constitui. Assim como no estádio do espelho nem a imagem do corpo, nem o corpo "próprio" possui individualidade prévia (por ser esse episódio constitutivo), podemos afirmar que o sujeito não preexiste ao Estado. Nessa abordagem estrutural nos posicionamos segundo o entendimento de que o eu se reconhece no Outro (Estado). Os referenciais do conhecimento especular, por não serem da ordem visual, têm origem no fato de que o sujeito é objeto do olhar do outro; a unidade dada ao sujeito não é da ordem de sua própria percepção; é dada de fora, é simbólica.

A teoria da psicanálise lacaniana pressupõe uma relação de dependência entre meio e indivíduo. Assim, podemos afirmar que a relação sujeito-Estado (Outro) não é “contratual” como preconiza o Direito (Teoria Geral do Estado) (Cintra, 1981). Para os juristas haveria um "contrato" entre os homens e o Estado para que este 
último lhes desse proteção. Nossa proposta é a de que a relação Estado-sujeito seja compreendida como não-contratual. Para isso tomamos a teoria materialista dos processos discursivos (Pêcheux, 1988) em que o discurso do Direito e o Poder Judiciário (Aparelho Ideológico do Estado) são compreendidos como meio de materializar a ideologia dominante nas relações entre o juiz e os depoentes. Sob esse raciocínio, podemos compreender o discurso do Direito e o Estado como produtores de um "tecido de evidências subjetivas" em que se constitui o sujeito e, ao mesmo tempo, como algo que dissimula o assujeitamento no interior dessas relações (pela própria ideologia e pelo inconsciente). Esse efeito de ocultamento do assujeitamento é explicado por Michel Pêcheux (1988), através dos dois esquecimentos: o sujeito se constitui a partir do esquecimento daquilo que o determina (a lei), quando se identifica com uma formação discursiva dominante e reinscreve, em seu próprio discurso, elementos do "já dito", que fornece-impõe a realidade e seu sentido.

Quanto à visão psicanalítica, entendemos que é na linguagem que o sujeito se constitui, o que nos leva a articular à relação sujeitoEstado o conceito de sujeito do inconsciente (Freud, 1996; Lacan [1949][1960]1998; [1953-1954]1986; [1954-1955]1987; 1992; [1957]1998). Os conceitos de necessidade, demanda e desejo na experiência do sujeito jurídico, situado dentro do discurso jurídico, o tornam sujeito do "desejo do desejo do Outro" (Dor, 1989). A relação sujeito-Estado, situada na ligação entre ideologia e inconsciente é complexa, pois as "estruturas-funcionamento" (Pêcheux, 1988), trabalham no sentido de dissimular sua própria existência na constituição do sujeito. A interpelação vincula aparelho repressivo e aparelho ideológico de Estado, vincula sujeito de direito e sujeito ideológico, mostrando que existe algo que fala ao sujeito, antes que ele possa dizer: "Eu falo" (Pêcheux, 1988). A transparência e a linearidade da língua trazem imperativos do poder jurídico: o Estado impõe "como" e "quando" falar, o que justificaria os recortes do juiz nas falas. A Lei, ao determinar "como" e "quando" falar durante uma audiência perante o juiz, traça o caminho do desejo do sujeito. Desse modo o Estado tem função essencial na determinação do sujeito, 
aparecendo, para este, imagem especular desejável, que fala antes de o sujeito falar.

\section{A ficção da gramática do discurso do Direito na cadeia discursiva}

Os ritos dos atos realizados na audiência, previstos na lei (Brasil [1973] 2007, arts. 346, 445-446, 451 e 457), atuam ideologicamente no sentido de que não só o depoente, mas também o juiz, o escrevente de sala e o advogado a eles se submetam sem que isso lhes cause estranheza, fazendo com que se submetam "livremente". Os atos de enunciação dos sujeitos numa audiência se relacionam a algo que está além deles, ou seja, à lei, que dita o sentido das falas em determinada direção. A lei dá ao juiz o poder de interrogar, já que a ele cabe "dirigir os trabalhos da audiência” (Brasil, CPC, [1973], 2007: art. 446). Nos recortes abaixo, o juiz (J) interroga o sujeito-depoente (T) e este, responde de modo dispersivo e, posteriormente, o juiz dita ao escrevente de sala o que deve constar do termo de audiência.

(transcrição do depoimento):

$\mathrm{J}$ : O que que a senhora sabe?

T: É que ele morou lá um ano ... um ano de:: ... sem pagar aluguel sem pagar condomínio e que foi movida uma ação de despejo contra ele e ele saiu deixou danos no imóvel

J: Que ... que danos foram esses?

T: Pintura geral do imóvel limpeza controle que ele entregou ... ele entregou a chave ao do ... à doutora $(\mathrm{V})$ a advogada ... ao doutor $(\mathrm{X})$ no escritório dele ... aí o controle não funcionava ... limpeza geral ... pintura geral no imóvel ...

(ditado do juiz):

J ((ditando à escrevente)): Foi a depoente quem fez a vistoria de entrada e saída do imóvel ... Lembra-se que o imóvel não foi devolvido nas mesmas condições em que foi locado ... vírgula ... já que o locatário não fez a pintura geral

(digitação do escrevente, grifo nosso):

[...] Foi a depoente quem fez a vistoria de entrada e saída do imóvel. Lembra-se que o imóvel não foi devolvido nas mesmas condições em 
que foi locado, já que o locatário não fez a pintura geral nem a limpeza $[\ldots]$

Chamamos a atenção, na análise desses recortes, para o fato de que o discurso do Direito obscurece a realidade ao fazer correspondência entre as palavras, trazendo consigo, portanto, um fetichismo, algo a que se atribui a virtude extraordinária de "correspondência" entre o que o depoente falou e o que foi escrito pelo escrevente de sala sob o ditado do juiz. Nessa gramática do discurso do Direito, o "deverser” da norma jurídica estabelece os ritos da audiência, contém uma repressão preexistente à obrigação de depor (pois os conflitos só podem ser resolvidos por meio do Poder Judiciário), equipara-se a um imperativo e a um instrumento de medida (Miaille, 1979:8586). Assim, essa gramática não diz o que deve ser, mas já "aquilo que é” (op. cit.:90). Quando a norma jurídica nos faz crer que é fonte de valor, "entra a fetichização", momento em que atribuímos à norma uma "qualidade que parece intrínseca (a obrigatoriedade, a imperatividade), justamente quando esta qualidade pertence não à norma mas ao tipo de relação, de relação social real de que esta norma é expressão" (Miaille, 1979:90).

Ao enunciar, o sujeito ( $\mathrm{T}$ ) dá abertura a outros sentidos que não os impostos pelo discurso do Direito. $\mathrm{O}$ sentido passa por um deslocamento, dando lugar à deriva, ao deslize no depoimento de (T). Há, no entanto, busca de estabilidade de sentido de sua fala na composição do respectivo termo pelo juiz (J), de modo a tentar manter sentido estável, quando transforma narrativas elaboradas na atividade linguageira em narrativas enquadradas pelo discurso do Direito. A fala de (T), dispersa, torna-se concisa no ditado do juiz (J). Ambas as falas remetem aos mesmos fatos, porém não constroem as mesmas significações. No "termo de audiência" digitado pelo escrevente de sala sob o ditado do juiz são eliminadas as supostas "falhas" do sujeito-depoente (T), restando um discurso "unificante" do Direito. A significação do que foi enunciado tem um valor jurídico, determinado de antemão pela lei e determinado pelos recortes do juiz (J), e isso torna possível a regularidade, a previsibilidade no sentido 
da enunciação do depoente (T). Há, nesse momento uma "sobreinterpretação" (Pêcheux, 2002:45) feita pelo juiz (J), que organiza as falas de (T) "ao modo de uma rede de paradigmas" (op. cit.: 46), que trabalha no sentido da fala de $(\mathrm{T})$ inserindo-lhe um sentido, uma única direção ideológica, coesão de sentido em lugar de dispersão.

Ao lado da constituição do sujeito do direito (sujeito do enunciado, da lei), na cadeia discursiva, há, também, a constituição do sujeito jurídico durante a enunciação feita em audiência. $O$ discurso do Direito, científico e racionalista traz consigo o recalque, o silenciamento, de modo a colocar o discurso jurídico como se fosse um resíduo, um objeto recalcado (Tfouni, 2008). Esse objeto recalcado retorna sob a concepção de um sujeito-falante (como origem do dizer) em que o inconsciente seria pré-condição concretizar esse dizer (Tfouni, 2008). Essas colocações conduzem à compreensão do discurso jurídico como discurso narrativo, o que, segundo Tfouni (2010a), constrói um lugar onde se instala a subjetividade, o modo pelo qual o sujeito organiza sua simbolização particular. Denominamos, portanto, sujeito jurídico aquele que emerge dos depoimentos narrados e transcritos, que escapam ao modelo imposto pela lei.

\section{Considerações finais}

Existe uma dificuldade de compreensão do funcionamento da gramática do discurso do Direito, de seus efeitos ideológicos, que pode ser dissimulada, apreendida na "intersubjetividade falante" (Pêcheux, 1988), ou seja, quando atentamos para a história que se inscreve no discurso do sujeito, quando observamos outro valor em sua enunciação, que não o ditado pela lei. Conforme lição de Elia (2004) a sujeição do sujeito ao inconsciente se articula sem seu arbítrio, momento em que se dá a produção de atos falhos e lapsos discordantes das características que deveriam estar presentes no sujeito do direito, sujeito do enunciado do termo de audiência ou da sentença. O "eu forte", autônomo e livre é uma ilusão que a ciência do Direito produz para o sujeito. A AD (Pêcheux, 1988) e o Letramento 
(Tfouni, 2010), permitem observar a constituição do sujeito jurídico na materialidade da língua, lugar do equívoco e da falha.

Entendemos que a gramática do discurso do Direito, ao interpelar o sujeito, dissimula a "subordinação-assujeitamento" (Pêcheux) deste ao grande Outro (Estado) sob a forma da autonomia (estrutura discursiva da forma-sujeito), de modo que a libido do eu permaneça investida na imagem do Estado (Outro), imagem esterilizante, nas palavras de Lacan ([1949]1998). Na esteira do pensamento de Lacan ([1972-1973]1985:20), para quem "o que diz respeito ao ser, ao ser que se colocaria como absoluto, não é jamais senão a fratura, a rachadura", nossa proposta de romper com essa gramática cumpre a finalidade de mostrar como opera o inconsciente na determinação do sujeito com a alteridade.

Recebido em: março de 2012 Aprovado em: abril de 2012 di_motta61@yahoo.com.br lvtfouni@usp.br

\section{Referências bibliográficas}

ALTHUSSER, L. Ideologia e Aparelhos Ideológicos do Estado, In: Slavoj Zizek org., Um mapa da ideologia. Rio de Janeiro: Contraponto, 1999, p. 105-142.

BOURDIEU, P., O poder simbólico, $2^{\text {a }}$ Ed., Rio de Janeiro: Berthand Brasil, 1998

BRASIL, Código de Processo Civil, Lei 5869, de 11.01.1973, In NEGRÃO, T. e GOUVÊA, J., $39^{a}$ Ed., São Paulo: Saraiva, 2007

BRASIL, Constituição da República Federativa do Brasil, promulgada em 05.10.1988, org. Yussef Said Cahali, 5ª ed., São Paulo: RT, 2003

CINTRA, A.C., GRINOVER A. e DINAMARCO C., Teoria Geral do Processo, $3^{\text {a }}$ ed, São Paulo: RT, 1981

DINAMARCO, C., Fundamentos do Processo Civil Moderno, tomo I, São Paulo: Malheiros Editores Ltda, 2000 
DOR, J., Introdução à leitura de Lacan: o inconsciente estruturado como linguagem, Porto Alegre: Ed. Artes Médicas, p.139-147, 1989

ELIA, L., O conceito de sujeito, Rio de Janeiro: Ed. Jorge Zahar , 2004

FREUD, S., Totem e tabu, In Obras psicológicas completas, Trad. Jayme Salomão, Rio de Janeiro: Imago, vol. XIII, p. 21-162, 1996

GINZBURG, C., Mitos, emblemas, sinais: morfologia e história, São Paulo: Ed. Companhia das Letras, 1989

GUIMARÃES, E., Semântica do acontecimento: um estudo enunciativo da designação, Campinas: Pontes, 2002

HAROCHE, C., Fazer dizer, querer dizer, São Paulo: Ed. Hucitec, 1992

LACAN, J., Seminário I. Os escritos técnicos de Freud, (1953-1954), Rio de Janeiro: Jorge Zahar, 1986

, O seminário - livro 2 - o eu na teoria de Freud e na técnica da psicanálise (1954-1955), Rio de Janeiro: Jorge Zahar, 1987

A instância da letra no inconsciente ou a razão desde Freud (1957), In LACAN, J., Escritos, Rio de Janeiro: Jorge Zahar, 1998

, O estádio do espelho como formador da função do eu (1949), In LACAN, J, Escritos, Rio de Janeiro: Jorge Zahar, 1998, p. 96

, Observação sobre o relatório de Daniel Lagache: "Psicanálise e estrutura da personalidade" (1960), In LACAN, J., Escritos, Rio de Janeiro: Jorge Zahar, 1998, p. 653

, O seminário livro 20: mais ainda, (1972-1973), Rio de Janeiro: Jorge Zahar, 1985

, O seminário, livro 8: a transferência, trad. Dulce Duque Estrada, Rio de Janeiro: Jorge Zahar, 1992

LAGAZZI, S., O juridismo marcando as palavras: uma análise do discurso cotidiano. Dissertação de Mestrado pelo programa de Pós-Graduação em Linguística, IEL-UNICAMP, 1987

LEGENDRE, P. Jouir du povoir (Traité de bureaucratie patriote), Éd. Minuit, Paris, 1976

MELEnOTTE, G., Sustancias del imaginário, trad. de Silvia Pasternac, México: Epeele, 2006

MIAILlE, M. Uma Introdução Crítica ao Direito, trad. Ana Prata, Lisboa: Moraes Editores, 1979 
MILNER, J-C, O amor da língua, porto Alegre: Artes Médicas, 1987

ORLANDI, E, Interpretação; autoria, leitura e efeitos do trabalho simbólico, Petrópolis, RJ: Vozes, 1996

PÊCHEUX, M., Semântica e discurso: uma crítica à afirmação do óbvio, Campinas: Ed. Unicamp, 1988

2002

O Discurso: estrutura ou acontecimento?, Campinas: Ed. Pontes,

SILVA, D. P., Vocabulário Jurídico, 10ª . Ed., Rio de Janeiro: Editora Forense, 1987

TFOUNI, L., Letramento e Analfabetismo. Tese de livre-docência, FFCLRP - USP, Ribeirão Preto, 1992

, Letramento e alfabetização, 9a ed., São Paulo: Ed. Cortez, 2010

, entrevista pessoal para discussão do texto da tese Letramento e discurso jurídico, FFCLRP-USP, maio de 2010a

, Mensagem e poesia. A atualidade de Saussure e Jakobson, ou sobre a verdade do sujeito (e do sentido) em deriva. In Gaspar, N. M. \& Romão, L. M. S. Discurso e texto: multiplicidade de sentidos na Ciência da Informação. São Carlos: EDUFSCAR 2008

TFOUNI, L. \& CARREIRA A., O sujeito submetido à linguagem, Revista Investigações da Universidade Federal de Pernambuco, vol. 20, n. 2, jul., Pernambuco, 2007

ZARKA,Y., Jacques Lacan. Psicoanálisis y política, Buenos Aires: Nueva Visión, 2004 